\title{
A cultura do lume e os montes galegos. Aproximación a unha relación histórica
}

Recibido: 22 Xaneiro 2009 / Aceptado: 4 Abril 2009

(C) IBADER- Universidade de Santiago de Compostela 2009

\begin{abstract}
Resumo O lume en épocas históricas, tivo, como ten na actualidade, unha múltiple casuística. Trataremos de analizar a distinta natureza que presentou ao longo da historia o lume no monte, pasando de elemento natural e ferramenta agropecuaria a mostra de descontento e protesta contra determinadas disposicións forestais que cambiaron as fórmulas de uso e xestión do espazo a monte. Isto é, indagaremos, a partir das fontes históricas dispoñibles e dos traballos xa existentes, na conversión do "lume no monte" en "incendio forestal". Pretendemos dar conta neste traballo das causas dos incendios no monte galego, tentando, por una banda, situar estes nun marco xeral en tanto que se trata dun fenómeno non exclusivo de Galicia e, pola outra, sinalar as singularidades que presenta fronte a outros espazos.
\end{abstract}

Palabras chave Lume $\cdot$ Incendio forestal $\cdot$ Monte $\cdot$ Galicia

\begin{abstract}
Forest fires had in the past, as nowadays, multiple causes. We will try to analize the different nature of forest fires in the long term. Fires changed from natural element and agropecuarian tool to an evidence of discontent and complaint against given forestry regulations that changed the ways of usage and management of forestry. That is, we will find out about the transformation from fire into arson, using the available historical sources and the existing studies. In this article we intend to show the historical meaning of arsons in the
\end{abstract}

Ana Cabana Iglesia

Historia Contemporánea e de América

Escola Politécnica Superior

Universidade de Santiago de Compostela

e-mail: ana.cabana@usc.es
Galician forest, framing them, on the one hand, as a general phenomenom, and, on the other hand underlying the singularities of Galicia.

Key words Fire · Forestry arsons · Forest · Galicia

\section{Introdución}

Cómpre dar conta da escaseza de investigacións que abordan a problemática dos incendios na historia de Galicia de maneira exclusiva (Balboa, 1999; Guitián, 1999; Seijo, 2005; Cabana, 2007), fronte a alta concentración de traballos que teñen como tema central a análise dos incendios "non históricos", é dicir, os ocorridos dende os anos oitenta do século XX en diante (Álvarez, 1992; Pérez Vilariño, 2004; Díaz-Fierros e Baamonde, 2006; Díaz-Fierros et al., 2007). Esta carencia de estudos debe ser posta en liña, entre outras razóns, coa debilidade das fontes para cuantificar o fenómeno. Non existen datos estatísticos ata 1961, e con diferenciación entre incendios en montes da Administración pública e privados, só despois de 1968 , ano en que se decretou a primeira Lei de incendios. Ademais de tardía, a fonte estatística, presenta fortes fraquezas. É sabido, por exemplo, que a súa fiabilidade é mínima para toda a década dos setenta. Antes desa data só contamos con información indirecta ou cualitativa que permite ter unha idea aproximada do ocorrido no monte galego como son os preitos xudiciais derivados da existencia dunha queima, que se rastrexan dende a época medieval, e as análises polínicas, que documentan prácticas pirófitas dende a Prehistoria (Guitián, 1999:150). Dende os anos corenta do século XX, a esta documentación histórica engádense os partes de incendios realizados polos gardas contratados pola Administración forestal. Trátase dunha fonte de grande interese pero que, debido a súa confección e ao seu grao de conservación, non consegue ser un rexistro senón un indicador de tendencias, ritmos e causas de lumes e incendios (Cabana, 2007). 


\section{O lume: unha constante histórica do manexo agrosilvopastoral}

Os incendios históricos teñen, como os actuais, unha orixe multicausal. As causas naturais, sobre todo as relativas á metereoloxía, están moi presentes nos incendios históricos, independentemente do factor antrópico. Isto é, a despoboación dun ecosistema non evita que o lume se inicie e propague. Alén da súa orixe natural, o lume ten sido ao longo da Historia unha ferramenta cultural para modificar o medio que non pode ser identificada como "incendio forestal". Humanos -e tamén homínidos- usaron o lume como un efectivo e eficiente método de conversión de recursos durante polo menos 250.000 anos (facilitar a caza; viaxar a través da densa vexetación; acto de guerra; etc.).Co desenvolvemento da agricultura, o lume pasou a ser a fórmula empregada para abrir novas terras ao cultivo ou para crear pastos para o gando doméstico. $\mathrm{E}$ o lume continúa a xogar un papel central nas estratexias agrarias actuais en determinados ecosistemas forestais de países subdesenvolvidos ou en vías de desenvolvemento (bosque tropical, bosque húmido, sabanas, etc.). No chamado "primeiro mundo" os lumes controlados empréganse como unha prescrición silvícola para control e redución da biomasa combustible -materia viva ou necromasa-. Así pois, o lume segue a ser unha ferramenta agropecuaria permitida e en uso de terra agraria e forestal en todo o planeta (Pyne, 1995 e 1997).

España non supón unha excepción. O lume é tamén unha realidade cunha forte presenza histórica, mesmo un elemento consubstancial nos montes estatais, tanto nos meditarerráneos (Sánchez Martínez, etal.,, 1999; Casero e González de Molina, 1997) coma nos atlánticos (Guitián, 1999). No caso galego o lume está ligado aos montes dende tempos inmemoriais dentro das lóxicas de uso agrosilvopastorais. Cómpre ter presente que historicamente o monte en Galicia foi un espazo agrario complemento básico e preciso das terras de labradío en tanto que operaba como provedor de adubo (toxo), espazo complementario de cultivo (rozas), lugar de pasto do gando e doutros recursos naturais básicos para as explotacións agrícolas (madeira para apeiros, etc.) e para as unidades familiares rurais (leña, elementos construtivos, diferentes froitos, etc.) (Balboa, 1990; Grupo dos Comúns, 2006).

A conversión dos restos vexetais en cinza para poder adubar o terreo para a realización de rozas ou a queima de matogueiras para rexenerar pasto son usos tradicionais que se coñecen dende o Neolítico (Díaz-Fierros, 2006) e que non foron abandonados por completo ata que as innovacións tecnolóxicas que conformaron a coñecida como "revolución verde" (motorización, adubado químico, etc.) se xeralizaron na segunda metade do século $X X$. Ofelia Rey (1995) ten sinalado como en Galicia, á altura do século XVII,"se se ten en conta a produción cerealeira procedente do monte, as castañas obtidas nos soutos e os produtos gandeiros, cuxa dependencia de pasto non é cuesionable, pódese deducir que, a lo menos, entre unha cuarta parte e o $30 \%$ do produto agropecuario ten o seu fundamento na dispoñibilidade de terreo ocupado polo monte. Polo tanto, a maior ou menor abundancia deste inflúe de forma clara nas economías campesiñas. As estivadas foron para o campesiño galego, polo tanto, un medio básico de asegurar a súa subsistencia e reprodución biofísica en tanto que lle permitía dispor dunha colleita complementaria -que non ocasional- de cereal, igual que o era o pasto conseguido a través da queima.

A transcendencia do cultivo de cereal, concretamente de centeo, no monte ponse de manifesto nas enquisas realizadas para a confección do Catastro do Marqués de Ensenada, a mediados do século XVIII. Tamén queda reflectida a súa condición de aproveitamento habitual no monte comunal galego no traballo do xeógrafo francés Abel Bouhier nos anos setenta do século XX (Bouhier, 2001). Nos douscentos anos que hai entre os datos do Catastro e os recollidos por Bouhier pode comprobarse que a realización de rozas vai diminuíndo, se ben está lonxe de caer no abandono.

As estivadas consistían, basicamente, en arrincar terróns coa vexetación que cobre o solo, secalos e despois queimalos para obter as cinzas coas que abonar a terra. Esta práctica estaba tremendamente estendida por toda a Península Ibérica -son os "hormigueros" cataláns ou aragoneses (Olarieta et al., 2008; Miret, 2004)- e noutras latitudes aínda teñen vixencia, caso da bacía amazónica, rexións da India ou Bhutan (Steiner et al., 2004; Ramakrishman, 1992; Kerkhoff e Sharma, 2006).

As estivadas son tachadas por algún autor como unha práctica esquilmante que favorecía a erosión do solo e que impedía o crecemento de árbores, pero outros defenden que se trataba dunha práctica non tan agresiva co medio (Balboa, 1999). Nos atopámonos neste segundo colectivo. Entendemos que o campesiñado, se ben é certo que non é ecoloxicamente inocente durante o período histórico no que se realizaban as rozas- definido polo dominio da enerxía solar en canto a paradigma enerxético de produción- si dependía dunha "economía ecolóxica". Estamos lonxe de defender a teoría do "ecoloxismo dos pobres" de Martínez Alier (2005), que concede a todos os grupos subalternos e dominados a condición de ecolóxicos nas súas prácticas de apropiación da natureza, pero consideramos que os campesiños estaban máis cerca da eficiencia ecolóxica ao adaptar o mercado aos recursos naturais e non ao contrario. Nesta liña cómpre sinalar que a colleita mantíñase só durante dous anos no mesmo lugar. Bouhier sinala que os campesiños se arranxaban para que a duración dos ciclos de estivadas fose tal que os rendementos non caesen por debaixo do 3 a 1, para o cal non dubidaban en alongar o intervalo de descanso. Os devanditos descansos estaban fixados xa no Antigo Réxime. Na antiga provincia de Lugo, por exemplo, o período medio das roturación do monte cerrado de primeira calidade era de 21 anos, 28 na segunda e 34 na terceira, mentres que nos montes abertos o ritmo medio era de 27,4 nos mellores terreos, 36,5 nos medianos e de 41 nos inferiores (Rey, 1995). Todo parece indicar que existe unha preocupación polas condicións do terreo a hora de fixar os espazos e os ritmos da estivada (evitar lugares de pendente, condicións de aridez, etc. (Bouhier, 1991; Balboa, 1990). 
Polo tanto, non se pode entender a existencia e uso do lume na superficie de monte en Galicia sen ter presente a cultura forestal e a significación de mencionado espazo para as súas xestoras, as comunidades rurais. Non será ata que esta consideración mude, nomeadamente cando os intereses forestais empecen a ser valorados e, a raíz diso, cando o Estado artelle o seu control sobre os montes, que estas prácticas se pasen a considerar ilegais e punibles. As autoridades tentaron eliminar o lume do monte criminalizando a actividade agraria e definindo as queimas de pastores e agricultores como "incendios". Polo tanto, os primeiros incendios non foron máis que a continuación de prácticas tradicionais e mostras da cultura forestal (estética do monte limpo, erradicación de alimañas e parásitos, etc.) pero nun marco político e económico que impoñía unha nova xeira para o monte, a súa etapa forestal.

\section{O lume como fórmula de protesta}

Evidentemente, estamos ante unha evolución que se deu a nivel xeral, non se trata dunha reacción exclusiva das comunidades galegas nos seus montes. Tense contextualizado o valor simbólico do incendio forestal nas comunidades campesiñas de diferentes partes do mundo, demostrando que o que era un lume factor de rexeneración vexetativa do monte acadou un novo rol: o de ser un elemento de reprobación ante un patrón de xestión forestal homoxéneo imposto polos diferentes Estados. É dicir, o uso do lume na paisaxe evoluíu dende unha técnica de construción e manipulación do agroecosistema a unha forma destrutiva de protesta emprendida polos grupos de campesiños afectados por lexislacións forestais que rachaban as súas lóxicas de uso tradicionais. Ambas as naturezas do lume, a de ferramenta agropecuaria e a e fórmula de protesta, conviviron no tempo pero a segunda deixou de ser puntual, como o era historicamente, para xeneralizarse na contemporaneidade.

Dita transición no significado do lume dase nun marco máis amplo como é un cambio no que Guha e Gagdil denominaron "modo de uso dos recursos" (Guha e Gagdil, 1993). Este concepto integra diferentes variables de acceso, distribución, asignación e propiedade dos recursos naturais nunha sociedade e nun momento histórico dado. Aplicados á situación histórica dos montes galegos, permite diferenciar dous modos de uso, o modo de uso campesiño e o modo de uso industrial. O conxunto de actividades que conforman o primeiro dos modos son as que forman parte do manexo agrosilvopastoral (pastoreo, recollida de materias primas, acopio de leña, carboneo de subsistencia, etc.). O segundo modo de uso ten como característica o aproveitamento forestal en exclusiva. A imposición deste modo de uso ao longo do século XIX destinou a moitas das accións do sistema agrosilvopastoral á ilegalidade, pasando a tacharse de exemplos de "delincuencia forestal". As comunidades campesiñas viron así condenadas prácticas que tiñan inseridas no seu devir cotián, e que eran básicas nos seus sistemas de economía orgánica, o que desencadeou un grave conflito socioambiental.
Casos de estudo de Inglaterra, Australia, Arxelia, India ou o sur dos Estados Unidos serviron a diferentes investigadores para ilustrar como os incendios nos montes son un indicador do descontento campesiño ante a perda de dereitos de propiedade ou de xestión destes (Kuhlken, 1999; Guha, 1989; Pyne, 1995 e 1997). Esta conversión ten unha datación semellante no contexto mundial, o século $\mathrm{XIX}$, se ben hai casos como o inglés no que o incendiarismo como mostra da queixa campesiña fronte aos cercamentos (enclousers) e a conseguinte competencia comercial polos recursos e servizos forestais se adianta nun século (Hobsbawm e Rudé, 1978).

En España, e igualmente en Galicia, o lume ten operado como un axente destrutor de primeira orde sendo utilizado para dirimir a conflitividade entre grupos con intereses diverxentes no espazo a monte, tanto a nivel intracomunitario (entre dúas comunidades de montes por razón de lindes, dereitos de pasto, etc.) como intercomunitario (entre comunidades e a Administración ou entre as primeiras e a industria). Os incendios provocados coa intención de realizar unha protesta ou como forma de vinganza comezan a deixar de ser un elemento puntual no século XVIII, coincidindo co intervencionismo que a Administración borbónica exerceu sobre o monte para garantir o abastecemento da Mariña Real, pero tardaría aínda en converterse nun fenómeno de incendiarismo. Polo tanto, á "conflitividade intramodal", isto é, aquela que, seguindo a terminoloxía de Guha e Gagdil, se dá dentro do mesmo modo de uso, neste caso o modo de uso campesiño, acompáñaa tamén dende o Antigo Réxime unha incipiente "conflitividade intermodal", aquela que se define pola existencia dunha pugna entre modos de uso, dado que se establecen sobre principios sociais e ecolóxicos moi distintos (Guha e Gagdil, 1993). Esta segunda tipoloxía de conflitividade no monte galego dos século XVI-XVIII concrétase na introducción paulatina de aproveitamentos que respondían ao modo de uso industrial do monte (aproveitamentos forestais para as fábricas de curtidos, a construción naval, as ferrerías ou as forxas) que limitaban e/ou erosionaban o sistema de aproveitamento agrosilvopastoral.

No XIX, conforme avanzaba a implantación do modo de uso industrial, o monte erixiuse como unha fonte de conflito polo acceso aos recursos naturais. Leis agrarias e forestais foron as ferramentas que o Estado usou para impor un proceso crecente de desconexión entre agro e monte, mercantilizando ou directamente prohibindo estratexias de apropiación tradicionais. Esta aposta política por mudar os aproveitamentos do monte converténdoo nun espazo exclusivamente forestal, ou o que é o mesmo, a opción de subordinar a lóxica da subsistencia á lóxica do beneficio, foi ao que responderon os grupos de campesiños empregando, entre outras tácticas, o incendio de maneira masiva

O conflito intermodal de máis entidade na historia do monte galego aconteceu durante o réxime franquista e tivo como protagonista ao monte comunal. No resto do Estado, a diferenza de Galicia, o éxito das medidas desamortizadoras e privatizadoras liberais, aquí fracasadas, marcaron o momento álxido da conflitividade comunidades-Estado, de 
aí que os incendios tomaran nese período carta de natureza no monte (Herrera González et al., 2003; Cobo, 1992; Jiménez, 2002).

A simbiose histórica monte-agricultura e comunalcomunidades veciñais rompeuse en Galicia basicamente a partir dos anos corenta coa intervención da Administración forestal franquista. Á Lei Hipotecaria de 1941, pola que a titularidade dos montes comunais foi recoñecida aos consistorios municipais, hai que sumarlle a acción do Patrimonio Forestal do Estado, que promoveu repoboacións masivas impoñendo no comunal o uso forestal exclusivo a través da firma de consorcios, como ten analizado Rico Boquete (1995).
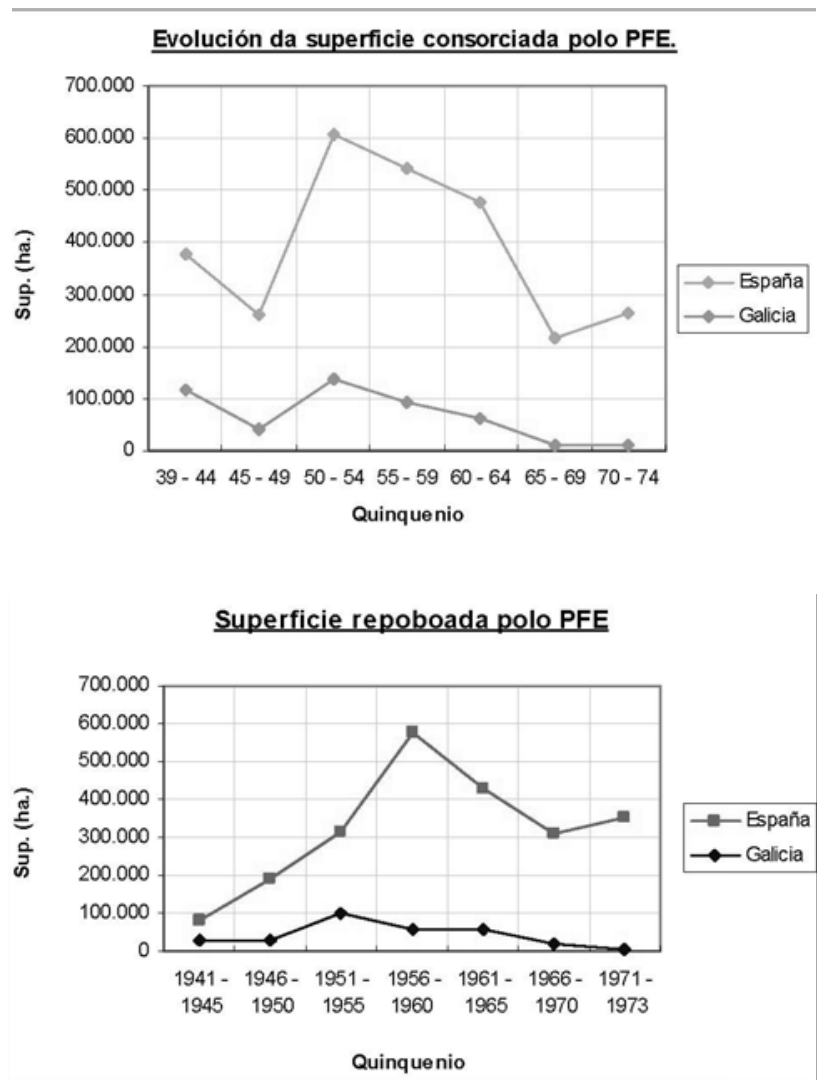

A imposición da prohibición de continuar realizando aproveitamentos propios do "modo de uso campesiño" contribuíu a que as comunidades galegas tiveran na política de repoboación forestal un foco xerador de descontento e conflitividade. Cabe incidir en que o conflito non se establece entre o aproveitamento forestal e o agrario, senón cun aproveitamento forestal de marcado carácter "produtivista -cunha clara vocación de servir ás necesidades de industrias papeleiras e celulósicas-" que se impón como incompatible cos usos tradicionais.

O fenómeno dos incendios forestais converteuse en Galicia dende os anos sesenta do século $X X$, debido a súa elevada frecuencia, intensidade e superficie afectada, nun dos motores da destrución das plantacións forestais realizadas polo réxime franquista. As causas desta ola incendiaria non deben buscarse en condicións climatolóxicas adversas nin nas causas accidentais senón no papel das comunidades que non renunciaron a perder o seu papel de propietarias e xestoras do monte comunal. Estas recorreron a numerosas formas de resistencia e accionaron diferentes modos de protesta e é nelas onde se debe encadrar unha gran parte dos incendios forestais ocorridos nos montes comunais durante o período franquista, tanto os xerados ex profeso para danar as plantacións forestais como aqueles que eran mostra da continuación duns usos agrosilvopastorais proscritos.

A relevancia que acadaron os montes galegos na obra de repoboación forestal ten parangón na preponderancia do número de incendios e de superficie afectada polos incendios no total español, como vemos nas gráficas precedentes (Subdirección General de la Riqueza Forestal, 1962-1985). Cómpre subliñar que, se ben os índices galegos sempre foron moi altos con respecto ao resto do Estado, estes duplicáronse a partir de finais dos anos sesenta, chegando nalgúns anos a ser incluso superiores que o dobre da taxa que representaban en décadas anteriores. Isto é indicativo de que nos montes galegos se vivía unha situación diferente á do resto do Estado que provocaba que ardesen en máis ocasións e que os incendios afectaran a máis hectáreas.

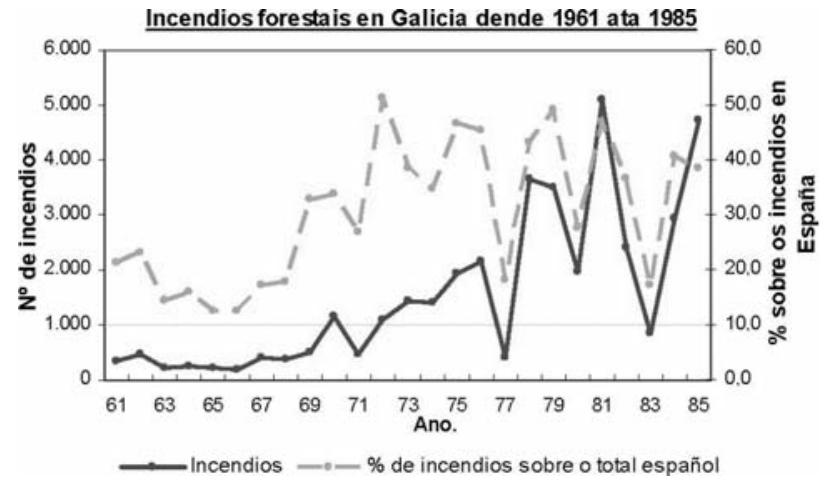

Superficie queimada en Galicia dende 1968 ata 1985

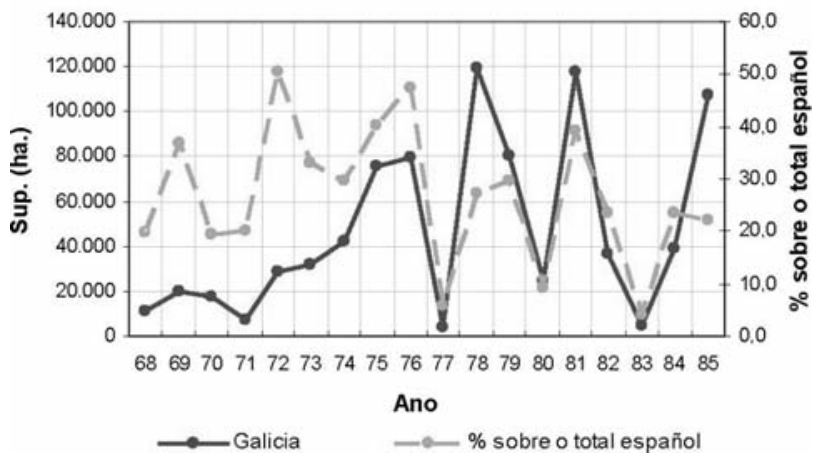

O ano 1968 estrea un novo periodo de conflitividade, o máis álxido, entre o Estado e as comunidades que non rematará antes de 1985 e que terá como consecuencia a evolución 
negativa da superficie arborada de Galicia, malia a que os traballos de repoboación continúen (Grupo dos Comúns, 2006). É a partir da aprobación da Lei de Montes Veciñais en Man Común (1968), cando os incendios acadan a súa máxima magnitude debido a que a citada lexislación intensificou o malestar das comunidades. Esta lei, malia a supor unha redefinición dos dereitos de propiedade adscribindo a titularidade dos montes aos veciños, non deixaba claro o carácter público ou privado daqueles, polo que seguían estando sometidos a plans de aproveitamento impostos polos concellos -quedando así asegurada a continuación das repoboacións forestais- e non permitía a xestión veciñal (Grupo de Estudos da Propiedade Comunal, 2004).

\section{Conclusións}

A introdución de limitantes á xestión comunal e ao uso agrosilvopastoral do monte foi un constante foco de conflitividade no monte, cando menos dende o Antigo Réxime, provocando que o lume complexizara a súa natureza e se volvera un modo de protesta ademais de ferramenta agropecuaria tradicional. Durante o século XIX os Estados Liberais europeos, incluído o español, aplicaron políticas forestais que impoñían a privatización e a comercialización dos montes en contra da multifuncionalidade que a esta superficie lle conferían as comunidades rurais, o que deu lugar a unha fonda conflitividade intermodal da que os incendios foron unha mostra. Foi o inicio do fenómeno do "incendiarismo": o emprego do lume como fórmula de protesta a gran escala. En Galicia a imposición do modo de uso industrial no monte, centrado na xestión forestal dos montes comunais, ocorreu máis tardiamente no tempo, na segunda metade do século $X X$, durante a ditadura franquista. A resposta das comunidades non diferiu da dada noutras latitudes. Está comprobado que a adopción do lume como forma de protesta é doada para todas aquelas comunidades que teñen nel un elemento cotián e de manexo coñecido, caso das galegas. A cultura forestal existente, baseada nas prácticas agrosilvopastorais tradicionais no espazo a monte, o descontento social, primeiro fronte ás repoboacións masivas e despois durante o proceso de devolución da titularidade e xestión dos comunais, e a nova realidade do monte, dende ese momento xa "forestal" en puridade, converteron os incendios nun fenómeno endémico nos montes galegos.

\section{Bibliografía}

Álvarez Sousa, A. (1992). Os incendios forestais. Análise sociolóxica do sector forestal galego, Vigo, Xerais.

Sánchez Martínez, J.D., Araque Jiménez, E., Pulido Mérida, R., Moya García, E. (1999). Los incendios forestales en Andalucía y Extremadura durante el tránsito de los siglos XIX al XX". In: Araque Jiménez, F. (Coord.), Incendios Históricos. Una aproximación multidisciplinar, Baeza, Universidad Internacional de Andalucía, pp. 163-218.
Balboa López, X.L. (1990). O monte en Galicia, Vigo, Xerais.

Balboa López, X.L. (1999). El fuego en la historia de los montes gallegos. De las rozas al incendio forestal. In: Araque Jiménez, J., (Ed.). Incendios históricos una aproximación multidisciplinar. Baeza. Universidad Internacional de Andalucía. 258-274.

Bouhier, A. (2001). Galicia. Ensaio xeográfico de análise e interpretación dun vello complexo agrario. Santiago de Compostela, Xunta de Galicia/Obra Social Caixanova [orixinal de 1979].

Cabana Iglesia, A. (2007). Los incendios en el monte comunal gallego. Lugo durante el primer franquismo. Historia Agraria, 43: 555-577.

Casero Rodríguez, F. \& González de Molina, M. (1997). Mitos y realidades de los incendios forestales en Andalucía. In: González Alcantud, J.A. \& Buxó Rey, M.J., (Eds.). El fuego. Mitos, ritos y realidades. Granada. Anthropos. Diputación Provincial de Granada. 377-410.

Cobo Romero, F., Cruz Artacho, S. \& González de Molina, M. (1992). Privatización del monte y protesta social. Una primera aproximación a los delitos forestales (1836-1920). Agricultura y Sociedad, 65: 253-302.

Herrera González de Molina, A.S., Cruz Artacho, S., González de Molina Navarro, M.L., Núñez Delgado, M., Ortega Santos, A. (2003). ¿Por qué se quemó el monte mediterráneo? Una relectura socioambiental de los incendios forestales en Andalucía Oriental, 1840-1890. In: Zunz, J.V. \& Ortega Santos, A. (Coord.). Las montañas del Mediterráneo, Granada, Centro de Investigaciones Etnológicas Angel Ganivet. 85-104.

Díaz-Fierros, F., Balboa, X. \& Barreiro, X.L. (Coord.) (2007). Por unha nova cultura forestal fronte aos incendios. Informes e conclusións. Consello da Cultura Galega. Santiago de Compostela.

Díaz-Fierros, F. \& Baamonde, P. (Coord.) (2006). Os incendios forestais en Galicia. Consello da Cultura Galega. Santiago de Compostela.

Fernández Leiceaga, X. (1990). Economía (política) do monte galego. Servicio de Publicacións Universidade de Santiago de Compostela. Santiago de Compostela.

Grupo de Estudios da Propiedade Comunal (2004). La devolución de la propiedad vecinal en Galicia (1960-1985). Modos de uso y conflicto de la propiedad. Historia Agraria, 33: $105-130$.

Grupo dos Comúns (2006). Os montes veciñais en man común. Xerais. Vigo.

Guha, R. (1989). The Unquiet woods: ecological change and peasant resistance in the Himalaya. Oxford University Press. Delhi.

Guha, R. \& Gadgil, M., (1993). Los hábitats en la Historia de la Humanidad", Ayer, 11, pp. 49-119. 
Gutián Rivera, L. (1999). Los incendios forestales a través de la Historia: pervivencias y cambios en el uso del fuego en el noroeste peninsular. In: Araque Jiménez, F. (Coord.). Incendios Históricos. Una aproximación multidisciplinar. Universidad Internacional de Andalucía. Baeza.149-162.

Hobsbawm, E. \& Rudé, G., (1978). Revolución industrial y revuelta agraria: el Capitán Swing. Siglo Veintiuno. Madrid.

Jiménez Blanco, J.I. (2002). El monte: una atalaya en la historia. Historia Agraria, 26: 143-172.

Kerhhoff, E. \& Sharma, E. (2006). Debating shifting cultivation in the Eastern Himalayas. Farmer's innovations as lessons for Policy. ICIMOD.

Kulken, R. (1999). Settin'the woods on fire: rural incendiarism as protest. Geographical Review, 89, $n^{\circ} 3: 343-$ 363.

Lage Picos, X.A. (2003). Bosques, sociedades y cultura forestal en Galicia. Universidade de Vigo. Vigo.

Miret i Mestre, J. (2004). Las rozas en la Península Ibérica. Apuntes de tecnología agraria tradicional. Historia Agraria, 34: 165-193.

Ortega Santos, A. (2001). Montes comunales en sociedades mediterráneas: modos de uso de los recursos naturales en Andalucía Oriental, siglos XVIII-XIX. In: González de Molina, M.; Martínez Alier, J. (Eds.). Naturaleza transformada. Icaria. Barcelona. 367-391.

Pérez Vilariño, J. (2004). Incendios forestales y reconstrucción social del monte. In: Díez Nicolás, J. et al. (Coord.). Reflexiones sociológicas. Homenaje a José Castillo Castillo. CIS. Madrid. 651-678.

Pyne, S.J. (1995). World fire: the culture of fire on Earth. Herny Holt. New York.
Pyne, S.J. (1997). Vestal fire: an environmental History. Told through fire, of Europe and Europe's encounter with the world. University of Washington Press. Seatle.

Ramakrishnan, P.S. (1992). Shifting agricuture and sustainable development. An interdisciplinary study from North-Eastern India". Man and the biosphere series, 10. UNESCO

Rey Castelao, O. (1995). Montes y política forestal en la Galicia del Antiguo Régimen. Universidade de Santiago de Compostela. Santiago de Compostela.

Rico Boquete, E. (1995). Política forestal e repoboacións en Galicia (1941-1971). Universidade de Santiago de Compostela. Santiago de Compostela.

Seijo, F. (2005). The politics of fire: spanish forest policy and ritual resistence in Galicia, Spain. Environmental Politics, vol. $14, n^{\circ} 3$ : 380-402.

Sineiro García, F. (2006). As causas estruturais dos incendios forestais en Galicia. In: Díaz-Fierros, F. \& Baamonde, P. (Coord.). Os incendios forestais en Galicia. Consello da Cultura Galega. Santiago de Compostela. 7792.

Steiner, C., Teixeira W.G. \& Zech W. (2004). Slash and char: an alternative to slahs and burn practiced in the Amazon Basin. In: Glaser, B. \& Woods, W.I. (Eds.). Amazonian Dark Earths: Explorations in space and time. Springer. Berlin. 183-193.

Subdirección General de la Riqueza Forestal. Servicio de Incendios Forestales. Los incendios forestales en España (1962-1985), Madrid, Ministerio de Agricultura e ICONA. 